\title{
Efficacy of an Analgesic and Anti-inflammatory Ayurvedic Medicine to Control Postoperative Pain
}

\author{
${ }^{1}$ Geetanjali Mandlik, ${ }^{2}$ Swapana Nayan, ${ }^{3}$ Maina Gite, ${ }^{4}$ Mukul Padhye, ${ }^{5}$ Suraj Pawar, ${ }^{6} \mathrm{P}$ Vinit, ${ }^{7} \mathrm{~N}$ Aishwarya, ${ }^{8} \mathrm{~K}$ Shruti
}

\begin{abstract}
Years ago, narcotics have been used as strong analgesics in relieving severe acute or chronic pain. However high dose of narcotics leads to many side-effects like respiratory depression, apnea, nausea, vomiting, physical and mental dependence, etc. Thus, narcotics along with other medicines known as nonsteroidal anti-inflammatory drugs (NSAIDs) are being increasingly used. The biggest risk with NSAIDs is severe and sometimes fatal gastrointestinal bleeding, increase in stomach acid, reduce the stomach's normal protective mucus layer, cause damage to the kidneys in people over 60; those with high blood pressure, heart disease, or pre-existing kidney disease. Ayurvedic medicines strengthen and enhance the body's own healing process. As all the ingredients are herbal, there is no fear of any adverse effects and hence effective results can be seen in relieving pain. The aim of our study is to evaluate the effectiveness of the study drug in providing efficient and adequate pain relief after minor oral surgical procedures.
\end{abstract}

Keywords: Alternative medicine, Ayurvedic medicine, Pain relief.

How to cite this article: Mandlik G, Nayan S, Gite M, Padhye M, Pawar S, Vinit P, Aishwarya N, Shruti K. Efficacy of an Analgesic and Anti-inflammatory Ayurvedic Medicine to Control Postoperative Pain. World J Dent 2015;6(3):164-168.

Source of support: Nil

Conflict of interest: None

\section{INTRODUCTION}

Pain is an unpleasant sensory and emotional experience due to a noxious stimulus associated with potential tissue damage. It is the most common and major symptom in most of the medical conditions affecting a person's quality of life.

To modulate the intensity and unpleasantness of pain, many other methods like distraction or excitement, hypnotic therapy, social support are practiced. Since many years narcotics have been used as strong analgesics in relieving severe acute pain but continuous use and high dose of these drugs leads to many side-effects

\footnotetext{
${ }^{1-3}$ Professor, ${ }^{4}$ Professor and Head, ${ }^{5-8}$ Lecturer

${ }^{1-8}$ Department of Oral and Maxillofacial Surgery, School of Dentistry, DY Patil University, Navi Mumbai, Maharashtra, India

Corresponding Author: Geetanjali Mandlik, Professor, Department of Oral and Maxillofacial Surgery, School of Dentistry, DY Patil University, Navi Mumbai-400706, Maharashtra, India, e-mail: pranay391989@gmail.com
}

like respiratory depression, apnea, nausea, vomiting, physical and mental dependence, etc. The other group, i.e. the nonsteroidal anti-inflammatory drugs (NSAIDs) are increasingly in use today. But these drugs also cause severe and sometimes fatal gastrointestinal bleeding, hyperacidity, which reduces the gastric normal mucus layer which acts as a protective layer, patients with hypertension, cardiac disease or pre-existing kidney disease are also at risk of kidney damage.

Since ancient times, ayurvedic medicines have been used to treat various ailments including pain. These are nature's herbal products which strengthen and enhance the body's own healing process and do not have adverse effects, if given in appropriate doses. The aim of our study is to evaluate the effectiveness of the study drug in providing efficient and adequate pain relief after minor oral surgical procedures (extraction of teeth).

When there is tissue destruction after trauma, the cell wall (cell membrane) undergoes lysis which leads to the production of arachidonic acid, a potent mediator for inflammation. The metabolic conversion of arachidonic acid through the lipoxygenase and the cyclo-oxygenese pathway produces leukotrines and prostaglandins which causes the pathological expression of inflammation, i.e. pain, erythema and edema.

The allopathic analgesic drugs are mainly from the NSAID group and the opioid group, such as morphine and opium and para-acetylaminophenol group like paracetamol.

Most commonly used drugs for postoperative pain management in oral and maxillofacial surgery are NSAIDs.

These drugs act in one or more of the following mechanisms:

- Anti-inflammatory effect: Modification of the inflammatory action

- Analgesic effect: Reduction of pain

- Anti pyretic effect: Lowering of raised body temperature

This is brought about by inhibition of arachidonic acid-cyclooxygenase pathway thus inhibiting the production of the prostaglandins and thromboxanes.

Disadvantages of NSAIDs:

The adverse effects of these drugs are nausea, vomiting, diarrhea or constipation, dyspepsia (impaired 
digestion), epigastric pain, bleeding, and ulceration (primarily gastric), rash, bronchospasm, rhinitis, edema, or an acute allergic reaction. Thus COX-1 is a constitute engine expressed in most tissues including blood platelets and at any site of inflammation and promotes the production of natural mucus lining that protects the inner stomach. COX-1 is involved in cell to cell signalling, tissue hemostasis, pain, clotting and protecting the stomach, where as COX-2 is involved in pain produced by inflammation.

Whereas on the basis of naturopathy, ayurvedic medicines are effective in most of the diseases and also are effective in complicated ailments without any adverse effects. Ayurvedic treatment is nontoxic, so it can be used safely as an alternative therapy or alongside conventional therapies.

Drugs useful in relieving pain are listed as Vedanasthapan Drugs by Charakachharya. The aim of the study is to prove the efficacy of the prepared ayurvedic medicine as an anti-inflammatory and analgesic during and after extraction of teeth under local anesthesia.

\section{MATERIALS AND METHODS}

Content of study drug:

The study drug has been formulated by the Department of Pharmacology at Dr DY Patil Ayurvedic College and Hospital, Navi Mumbai, Maharashtra, India.

- Hemidesmus indicus (Anantamul) $100 \mathrm{mg}$

- Ricinus communis (Shetverenda) $100 \mathrm{mg}$

- Moringa pterygosperma (Sajina) $100 \mathrm{mg}$

- Tinospora cordifolia (Gulancha) $125 \mathrm{mg}$

- Boerhavia diffusa (Rakta Punarnava) $75 \mathrm{mg}$ The properties of each ingredient are as follows:

\section{Hemidesmus indicus}

Hemidesmus indicus commonly known as Indian Sarsaparilla in English and Anantamool in hindi is a slender lactiferous semi erect or twinning shrub belonging to the family asclepiadaceae. It is a common medicinal plant widely used in Indian Systems of Medicine and also an official drug in Indian Pharmacopoeia and British Pharmacopoeia. The roots are used as antipyretic, antidiarrheal, astringent, blood purifier, diaphoretic, diuretic, refrigerant and tonic. ${ }^{1}$ The ethyl acetate extract of roots of $H$. indicus exhibited significant anti-inflammatory activity in both acute and subacute inflammation as revealed by significant inhibition of inflammation induced by carrageenain, bradykinin, S-hydroxytryptamine, employing granuloma pouch and cotton pellet implantation methods in rats. ${ }^{2}$ However it was found less effective than phenylbutazone or betamethasone, against granuloma pouch and cotton pellet implantation. It is ineffective in dextran induced inflammation. Anoop et al established the antiulcer activity of $H$. indicus. ${ }^{3}$ It acts through mucoprotective action selectively inhibiting prostaglandin PGF2 $\alpha$ exerts mucoprotective effect comparable with standard drugs ranitidine and omeprazole.

\section{Ricinus communis}

The castor plant (Ricinus communis L) is a robust perennial shrub of Euphorbiaceae family. The extract enhanced free radical scavenging activity of table DPPH radical, nitric oxide and hydroxyl in in vitro assay methods. Its root extract possesses significant anti-inflammatory activity in acute and chronic models in rats. The observed pharmacological activity may be due to the presence of phytochemicals like flavonoids alkaloids and tannins present in the plant extract with various biological activities. Asthma is a chronic inflammatory disorder of airway. Asthma is associated with change in the levels of eosinophils, mast cells, lymphocytes, cytokines and other inflammatory cell products. Its roots have been traditionally reported to be used in the treatment of inflammation, fever, ${ }^{4}$ asthma, bronchitis's and leprosy. The root also possesses antidiabetic activity. Leaves and stem show antibacterial and anti-inflammatory activity. ${ }^{5}$

\section{Moringa pterygosperma}

Moringa pterygosperma is the most well known species of Moringaceae family and has a wide range of medicinal uses with good nutritional value. This plant is found in the western and sub Himalayan tracts in India and other Asian countries. ${ }^{6,7}$ It is well distributed in the Philippines, Cambodia, America and the Caribbean Islands. ${ }^{8}$ All the parts of this tree have medicinal value and are used as medicines by people. The principle component pterygospermin in this plant has antimicrobial activity. The extract of the leaf showed inhibition of growth of pathogens like Staphylococcus aureus and Pseudomonas aeruginosa. ${ }^{10}$ The flowers, due to the presence of quercetin show hepatoprotective effect. ${ }^{9-11}$ They are considered to be antipyretic, acidic and bitter and reports claim that they have antimicrobial activity. ${ }^{12,13}$

\section{Tinospora cordifolia}

Tinospora cordifolia commonly known as Gulansha belongs to the family Meninspermaceae. Its main chemical components are tinocordifolin, tinocordifolioside, tinosponone, tinocordioside, cordioside, picroretine, colombine, and columbine T. cordifolia shows significant bactericidal activities. It improves bacterial clearance as well as improves phagocytic and intracellular bactericidal capacities of neutrophils. It also stimulates macrophage 
action. As a result, it stimulates immune system of body. It stimulates the function of macrophage and neutrophilia to produce leukocytosis. It inhibits lipid peroxidation and free radical formation. It decreases the capillary permeability and reduces number of disrupted mast cells. It exhibited insulin like action and significantly reduces the blood sugar level. It enhanced lipid peroxidation in the liver and blood of tumor-bearing models and accompanied by significant decreases in the activities of GSH-dependent antioxidant. It lowers the lipid levels especially cholesterol and LDL-cholesterol in body. It is used in burning sensation, hyperdipsia, intermittent and chronic fevers. It is used in inflammations, gout and skin diseases. ${ }^{14}$ It is useful in flatulence, dyspepsia, vomiting and stomach problems.

\section{Boerhavia Diffusa}

Also called spreading Hogweed, Punarnava, Shothagni, Rakta punarnava. A diffusely branched, pubescent or glabrous, prostrate herb. Boerhavia diffusa is herbal medicine for pain relief and other uses. It is believed to improve and protect eyesight. Boerhavia diffusa has diuretic properties and can be used in diabetes to lower blood sugar. ${ }^{15}$ It also shows antispasmodic and anti-inflammatory properties and are useful in urinary tract infection. The roots of this plant have, analgesic, anticonvulsant, laxative and expectorant properties. ${ }^{16}$ It has both diuretic and anti-inflammatory properties and therefore is useful in inflammatory renal diseases. Boerhavia diffusa was efficacious in the treatment of edema and ascites due to early cirrhosis and peritonitis, using a liquid extract prepared from either the dry or fresh plant. It is equally effective in edema secondary to heart disease from stenosis of the valves, in pleurisy and in other edematous conditions. ${ }^{17}$

\section{CASE SELECTION}

Mandibular molar teeth indicated for extraction because of acute, chronic pulpitis, periodontitis or pulp necrosis were selected irrespective of patients' gender. The selected patients are free from any positive medical history like hypertension, diabetes, tuberculosis, asthma and were not on any other analgesic. The age group was selected between 15 and 50 years of age. All the patients were given one uniform antibiotic of same strength one day preoperatively.

\section{METHODOLOGY OF THE STUDY}

One capsule of the study drug was prescribed for three times a day (day zero), the patient was called the next day for extraction. Extraction was done under LA with adrenaline. Patient was followed-up for the next 2 days and assessed for.

\section{Pain}

- 0 -No pain

- 1-Mild pain

- 2-Moderate pain

- 3-Severe pain

- 4-Unbearable pain

\section{Efficacy}

- 0 -Poor

- 1-Moderate

- 2-Good

- 3-Excellent

\section{Tolerability}

- 0 -Poor

- 1-Moderate

- 2-Good

- 3-Excellent

To eliminate bias assessment is done on basis of patients' response as well as investigators assessment. Side-effects are assessed in terms of nausea, vomiting, heart burn, gastritis and others.

The data were collected on 100 patients by observing them on four consecutive days. The readings on pain constitute ordinal measure and since same patients are being observed for 4 days, we used Friedman test (non parametric repeated measure analysis of variance (ANOVA) test for testing the significance of difference for observed pain.

\section{RESULTS}

There was significant difference in pain on all 4 days. There was a progressive decline in the pain over the 4 days. Thus, proving that, this ayurvedic medicine effectively reduces postoperative pain after extraction (Graphs 1 and 2).

Comparison of efficacy and tolerability: The efficacy and tolerability is being rated by patient and investigator independently on the scale of 0 to 3 .

Since, the scores constitute ordinal scale and groups are independent. We used Mann-Whitney $U$ test for the comparison.

Results of efficacy and tolerability: The observed values and statistical analysis show that the ayurvedic preparation is well tolerated by the subjects and has an acceptable level of efficacy (Graphs 3 and 4). 


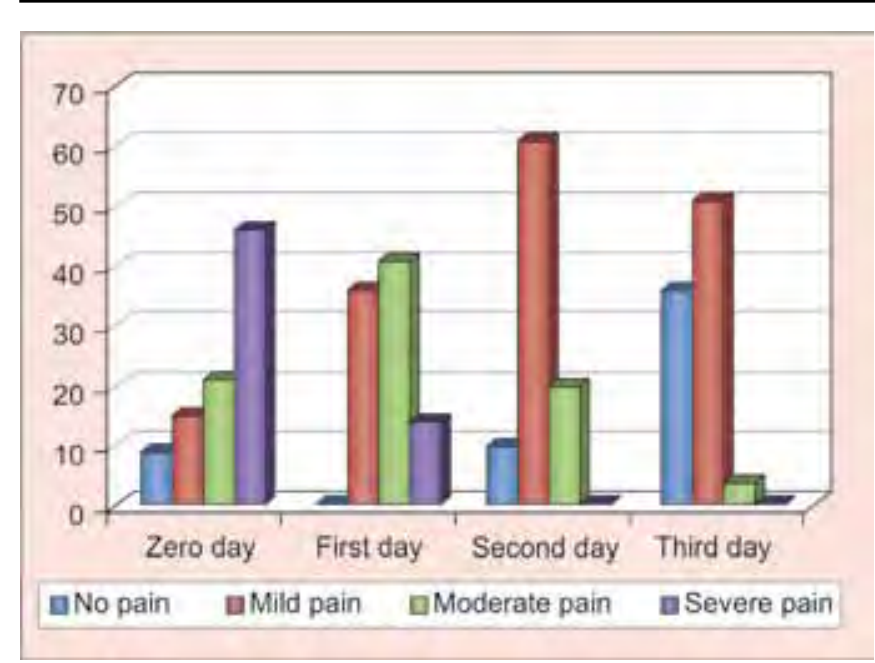

Graph 1: Day-wise distribution of pain

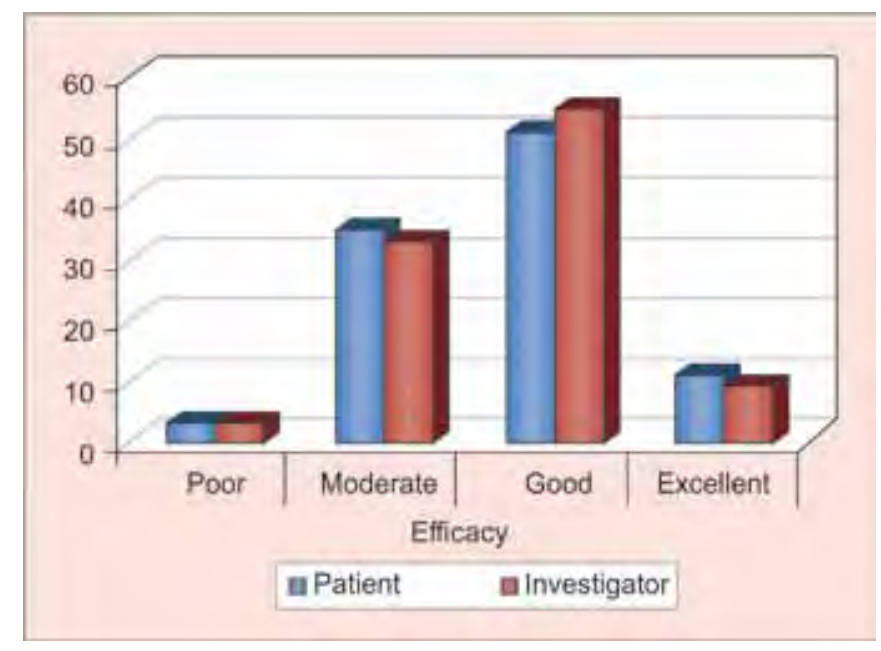

Graph 3: Results for efficacy

\section{DISCUSSION}

This study aims at analyzing the efficacy of an ayurvedic analgesic and anti-inflammatory medication on postoperative pain after extraction of mandibular molars. The results, though preliminary and based on a small group, are encouraging with no adverse effects. This preparation has ingredients $H$. indicus, $R$. communis, M. pterygosperma, T. cordifolia and B. diffusa, each of which has an anti-inflammatory and analgesic effect. Together they play an important role in reducing inflammation and postoperative pain. A total of $91 \%$ of the cases responded to the treatment and showed satisfactory results in which they were relieved of pain and signs of inflammation. ${ }^{18}$

\section{CONCLUSION}

From the result, it can be concluded that:

- The ayurvedic preparation used in this study effectively reduces postoperative pain after extraction.

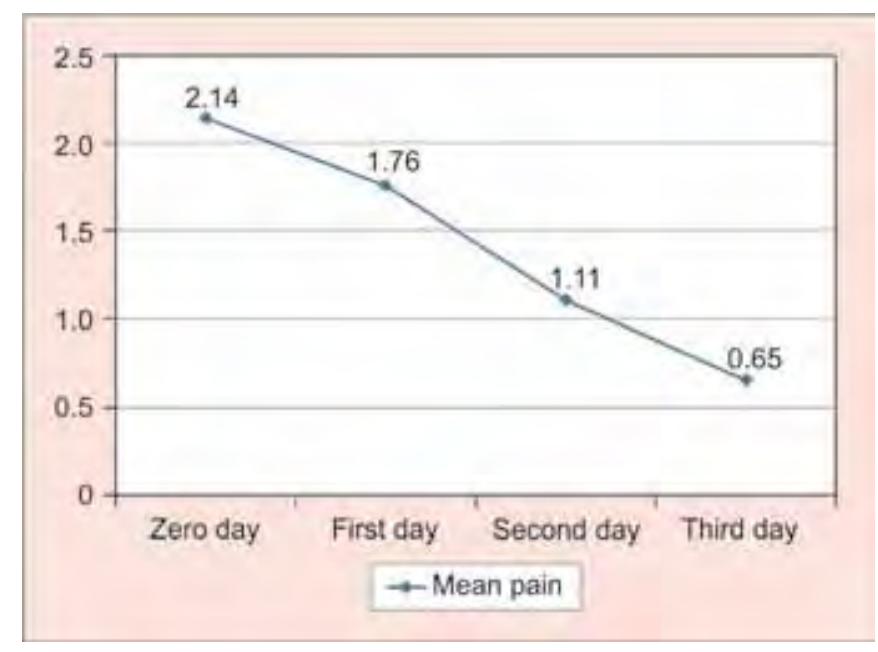

Graph 2: Mean severity

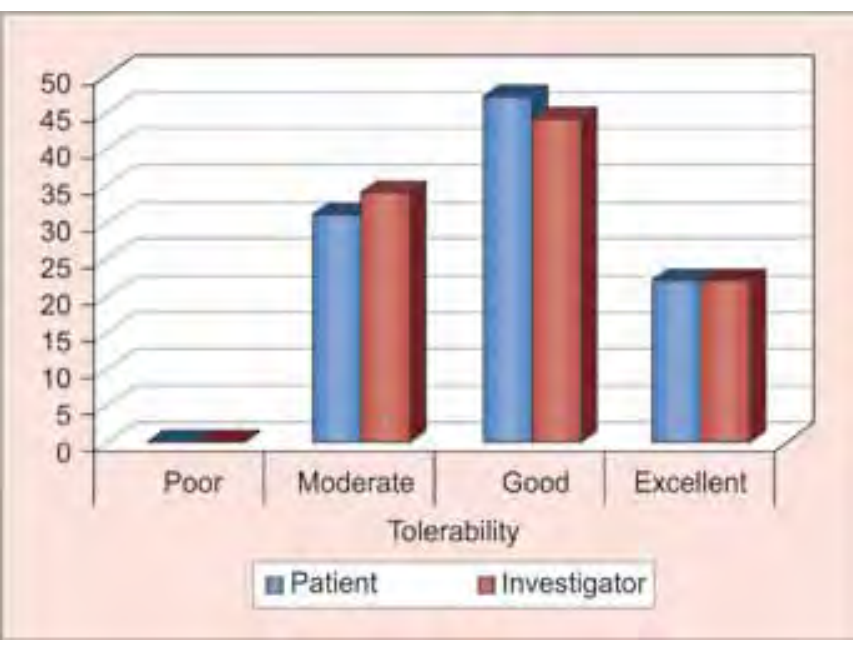

Graph 4: Results for tolerability

- There is progressive decline in the pain within 4 days of treatment but further extended study needs to be done with a larger sample size.

- No adverse effects were observed.

\section{REFERENCES}

1. Nadkarni AK. Indian Materia Medica. Popular Book Depot, Bombay, India 1989;1.

2. Dutta MK, Sen TK, Sikdar S. Some preliminary observations on the anti-inflammatory properties of hemidesmus indicus in rat. Ind J Pharmacol 1982;14:78.

3. Austin A, Jegadeesan M, Gowrishankar R. Antimicrobial activity of hemidesmus indicus var. indicus $\mathrm{R} \mathrm{Br}$. Against human isolates of Helicobacter pylori. Nat Prod Sci 2003;9:1-3.

4. Bousquet J, Bousquet PJ, Godard P, Daures JP. The public health implications of asthma. Bull World Health Organ 2005 83:548-554.

5. Luseba D, Elgorashi EE, Ntloedibe DT, Van Staden J. Antibacterial, anti-inflammatory and mutagenic effects of some medicinal plants used in South Africa for the treatment of wounds and retained placenta in livestock. S Afr J Bot 2007;3: 378-383. 
6. Somali MA, Bajneid MA, Al-Fhaimani SS. Chemical composition and characteristics of moringa peregrina seeds and seeds oil. J Am Oil Chemists' Society 1984;61(1):85-86.

7. Mughal MHS, Ali G, Srivastava PS, Iqbal M. Improvement of drumstick Moring (1) apterygosperma Gaertn: a unique source of food and medicine through tissue culture. Hamdard Medicus 1999;42:37-42.

8. Morton JF. The horseradish tree, moringa pterygosperma (Moringaceae): a boon to Arid Lands? Economic Botany 1991 45(3):318-333.

9. Gilani AH, Aftab K, Suria A, et al. Pharmacological studies on hypotensive and spasmolytic activities of pure compounds from Moringa oleifera. Phytoth Res 1994;8(2):87-91.

10. Das BR, Kurup PA, Rao PL. Antibiotic principle from moringa pterygosperma VII. Antibacterial activity and chemical structure of compounds related to pterygospermin. Ind J Med Res 1957;45(2):191-196.

11. Eilert U, Wolters B, Nahrstedt A. The antibiotic principle of seeds of Moringa oleifera and Moringa stenopetala. Planta Medica 1981;42(1):55-61.
12. Oliveira JTA, Silveira SB, Vasconcelos IM, Cavada BS, Moreira RA. Compositional and nutritional attributes of seeds from the multiple purpose tree moringaoleifera lamarck. J Sci Food and Agricul 1999;79(6):815-820.

13. The Wealth of India. A Dictionary of Indian Raw Materials and Industrial Products Raw Materials, Council of Scientific and Industrial Research, New Delhi, India 1960.

14. Singh SS, Pandey SC, Srivastava S, Gupta VS, Patro B, Ghosh AC. Chemistry and medicinal properties of tinospora cordifolia (Guduchi). Ind J Pharmacol 2003;35:83-91.

15. Kapur SK, Ethno-medico plants of Kangra valley (Himachal Pradesh). J Econ Taxonomic Bot 1993;17:395-408.

16. Raj KPS, Patel MR. Some medicinal plants of cambay and its immediate vicinity and their uses in Indian indigenous system of medicine. Ind Drugs 1978;15:145-152.

17. Nadkarni KM. Boerhaavia diffusa. Indian Material Medica, 3rd editor, Mumbai, Popular Book Depot 1954;202-207.

18. Grover HS, Deswal H, Bhardwaj A. Curcumin: a medicinal plant and its effects in medicine and dentistry. Int J Contemp Dent Med Rev, 2015. Article ID: 090115, 2015. 